\title{
Bioelectrical pattern discrimination of Miconia plants by spectral analysis and machine learning
}

\author{
Valéria M M Gimenez ${ }^{1}$, Patrícia M Pauletti ${ }^{1}$, Ana Carolina Sousa Silva ${ }^{2}$ and Ernane José \\ Xavier $\operatorname{Costa}^{2 *}$ \\ ${ }^{1}$ Universidade de Franca, Av. Dr. Armando Sales de Oliveira, 01, 14404600, Franca, São Paulo, Brazil \\ ${ }^{2}$ Faculdade de Zootecnia e Engenharia de Alimentos (FZEA), Departamento de Ciências Básicas (ZAB), \\ Universidade de São Paulo (USP), Av. Duque de Caxias Norte, 13635900. Pirassununga, 225, São Paulo, \\ Brazil \\ E-mail addresses: \\ vmmgimenez@yahoo.com.br (Valéria M M Gimenez); \\ patricia.pauletti@unifran.edu.br (Patrícia M Pauletti); \\ anacss@usp.br (Ana Carolina Sousa Silva); \\ *Corresponding Author: ernane@usp.br (Ernane José Xavier Costa) \\ date of submission: \\ number of tables : 3 \\ number of figures: 6 \\ word count: 2,631
}

Running title: Bioelectrical signal can characterize Miconia species 


\title{
Highlight
}

In loco characterization of the bioelectrical signals of two Miconia species in the time and frequency domain suggests that the species have distinct biological patterns.

\begin{abstract}
We have conducted an in loco investigation into the species Miconia albicans (SW.) Triana and Miconia chamissois Naudin (Melastomataceae), distributed in different phytophysiognomies of three Cerrado fragments in the State of São Paulo, Brazil, to characterize their oscillatory bioelectrical signals and to find out whether these signals have distinct spectral density. The experiments provided a sample bank of bioelectrical amplitudes, which were analyzed in the time and frequency domain. On the basis of the power spectral density (PSD) and machine learning techniques, analyses in the frequency domain suggested that each species has a characteristic biological pattern. Comparison between the oscillatory behavior of the species clearly showed that they have bioelectrical features, that collecting data is feasible, that Miconia display a bioelectrical pattern, and that environmental factors influence this pattern. From the point of view of experimental Botany, new questions and concepts must be formulated to advance understanding of the interactions between the communicative nature of plants and the environment. The results of this on-site technique represent a new methodology to acquire non-invasive information that might be associated with physiological, chemical, and ecological aspects of plants.
\end{abstract}

Keywords: bioelectrical signal, Cerrado, Miconia, non-invasive technique, oscillatory electric signals, power spectral density (PSD), random forests. 


\section{Abbreviations:}

AP: action potential

CM: Confusion Matrix

EA1: experimental area 1, in Pirassununga

EA2: experimental area 2, in Luíz Antônio

EA3: experimental area 3, in Pedregulho

LEP: local electrical potential

Ma: Miconia albicans

Mad: PSD of M. albicans of the dry area

Mc: Miconia chamissois

Maw PSD of M. albicans of the wet area

Mc: PSD of M. chamissois

MSE: Mean Squared Error

SP: systemic potential

OS: oscillatory signal

PSD: power spectral density

RF: Random Forests

RMSE: Root Mean Squared Error

VP: variation potential 


\section{Introduction}

The bioelectrical signals of plants can be classified into action potential (AP), variation potential (VP), systemic potential (SP), local electrical potential (LEP) (Fromm and Lautner, 2007), and oscillatory signal (OS) (Cabral et al., 2011). OS can be understood as a sum of all the other signals. OS can be acquired by invasive (electrode-intracellular needle) or non-invasive (disc-extracellular electrode) techniques. To characterize OS, visually distinct low-amplitude VP variations must be recorded. These variations show how OS behaves as a function of time and frequency. Oscillations occur under different conditions, thereby generating analyzable spectra (Cabral et al., 2011).

Thus, apparently immobile plants are in fact extremely dynamic beings. They are sensitive to environmental changes that may limit their chances of development and survival (Vodeneev, Akinchits, and Sukhov, 2015). Plants are subject to stimuli that trigger the transmission of information through signaling systems. These systems consist of networks that are integrated by connections between their elements, which are affected by hydraulic, chemical, or electrical action (Trewavas, 2007). After an excitation threshold is reached, stimulation produces an AP that is propagated to other plant cells and which may be associated with inhibition or expression of genes related to tolerance to various types of stress. APs are identified as electrical messages. In animals, APs take place in axons, where the ionic mechanism depends on $\mathrm{Na}^{+}$ion flow (inward depolarization) and $\mathrm{K}^{+}$ion output (repolarization) (Fromm and Lautner, 2007). In plant, AP generation and transmission imply changes in ion flow, such as $\mathrm{Cl}^{-}$and $\mathrm{K}^{+}$ efflux and $\mathrm{Ca}^{2+}$ inflow. This causes an ionic current and evidences that this mechanism is associated with water efflux and turgor loss (Volkov and Markin, 2015).

Plant electrical signals, which are mediated by cytosolic $\mathrm{Ca}^{2+}$ kinetics at the cell membrane level, usually generate a response within less than one second (Trewavas and Baluška, 2011). Therefore, electrical signals are crucial to plants. The speed at which information is transmitted distinguishes such signals from other forms of signaling and elicits ultrafast responses coordinated by appropriate cells (Davies, 2006; Fromm and Lautner, 2007; de Toledo et al., 2019). Over long distances, such signals are affected by chemical signals until they reach the vascular system or change gene expression, which can culminate in increased circulation, synthesis, and emission of volatile compounds like jasmonic acid and ethylenes into the atmosphere (Baluška and Mancuso, 2009; Volkov and Marquin, 2015). Volatile signals constitute local defenses and can be 
detected by weakly connected areas of the plant and by surrounding plants for many days (Baluška and Mancuso, 2009; Ali et al., 2013; Volkov and Markin, 2015). Mechanisms for converting electrical signals into functional responses have also been investigated (Vodeneev, Katicheva, and Sukhov, 2016). Some results have suggested a communication model based on AP transmission along highly reticulated vascular conduits (Dinant and Lemoine, 2010; Calvo, 2016; Calvo, Sahi, and Trewavas, 2017).

Studies have shown that the electrical potential of plants expands the possibilities of recognizing and classifying information fast in response to specific environmental stimuli (Volkov, 2012; Huber and Bauerle, 2016; Chen et al., 2016; Calvo and Friston, 2017). In this way, physiological and morphological aspects can be grouped into responses to these circumstances, indicating that plants prioritize signals among the several sources of stimulation (Calvo and Friston, 2017). Plants can still adapt to environmental fluctuations by generating complex systems that can withstand these variations with greater stability (Souza, Pincus, and Monteiro 2005; Volkov and Markin, 2015; Volkov et al., 2017; Pereira et al., 2018). Therefore, electrical signals are physical entities that can carry information about the nature or behavior of a given phenomenon and which vary over time and space (de Toledo et al., 2019), so that plants can be considered a network of transducers that receive and emit different types of signals. The electrochemical-biochemical signal plays an important role in the communication between internal components associated with biotic or abiotic environmental conditions, allowing the physiological activities of plants to be characterized (Hasegawa et al., 2000).

Additionally, computer technology and mathematical models have evolved, allowing a plant's electrical signal to be collected, interpreted, encoded, and transformed into a new "language" that can reflect plant physiology and the interaction of the plant with the environment at the individual level. This helps to understand the principles and relationships that govern the plant's organizational behavior and suggests bioelectrical models (Souza et al., 2017).

In the context of the omic sciences, electroma means the totality of all ionic currents of any living entity from the cellular to the organismal level that is vital for the maintenance and definition of life, whereas cellular "death" is the moment when the ability to perceive the electrical dimension is irreversibly (excluding regeneration) lost (De Loof, 2016). 
Bioelectrical signals obtained from plants with amplifier equipment generate large datasets that can be processed by digital signal processing and machine learning techniques. Power spectral density (PSD) estimation is a relevant digital signal processing (DSP) technique that can be used to analyze periodic and random signals (Proakis and Manolakis, 1996). Numerous problems in signals acquired from biological systems can be tackled by applying spectrum analysis as a preliminary measurement before further processing is performed (Fong et al., 2016). Sophisticated spectrum measurements can be used to obtain information from bioelectrical signals; for example, EEG (Manshouri, Maleki, and Kayikcioglu, 2018; Costa and Cabral, 2000) and ECG (Baldin et al., 2020).

Spectrum analysis by PSD encompasses various measurements. For this reason, this topic has received close attention and has been employed in several research areas. Moreover, applying a machine learning algorithm like Random Forests (RF) is useful when such extensive arrays of data are analyzed (Verikas, Gelzinis, and Bacauskiene, 2011). RF is a bootstrapping classification tool that generates decision trees by using different sets of randomly selected input variables, to make a prediction. The RF algorithm was introduced by Breiman Leo in 2001 (Breiman Leo, 2001), and it can be employed for classification and regression. It can be successfully applied in statistical analysis because it is not complex, has few parameters to tune, and can tackle highdimensional feature spaces and complex data structures (Oparin et al., 2008; Hernandez et al., 2008).

The accumulated knowledge about different electrical signals in plants and their relationship with short- and long-distance transmission of physiological responses has been established in a controlled environment, mainly for monitoring physiological aspects related to plant development and for understanding agronomic factors related to production. However, this resource has not been used to understand plant behavior in loco. In this scenario, this study aimed to collect the oscillatory bioelectrical signals of two Brazilian Cerrado species of Miconia (Melastomataceae) in loco and to verify if the patterns of the signals differ in terms of spectral density. 


\section{Materials and methods}

\section{Study Areas}

The bioelectrical signals were collected in three fragments of Cerrado in different locations of the state of São Paulo. Two of these fragments are part of conservation units: Estação Ecológica de Jataí (EEJ), in Luiz Antônio ( $21^{\circ} 33^{\prime} \mathrm{S}$ and $\left.47^{\circ} 51^{\prime} \mathrm{W}\right)$, and Parque Estadual Furnas do Bom Jesus (P.E.F.B.J.), in Pedregulho (20 08' S and $47^{\circ} 16^{\prime}$ W). The third fragment is located at the University of São Paulo in Pirassununga ( $21^{\circ} 36^{\prime}$ $\mathrm{S}$ and $\left.47^{\circ} 15^{\prime} \mathrm{W}\right)$. These fragments have distinct characteristics.

According to the Köpen-Geiger climatic classification, experimental area 1 (EA1, Pirassununga) presents Cwa climate, which represents humid temperate climate with dry winter and hot summer; experimental area 2 (EA2, Luiz Antônio) is classified as Aw, corresponding to tropical climate with dry winter season; and experimental area 3 (EA3, Pedregulho) corresponds to $\mathrm{Cwb}$, where the climate is temperate humid with dry winter and temperate summer.

In each of the three study areas, plots of $40 \mathrm{~m}$ x $50 \mathrm{~m}$ were established in two Cerrado phytophysiognomies: Cerrado stricto sensu (dry environment), where seven Ma (Miconia albicans) specimens were sampled, and gallery forests or areas close to a watercourse (wet environment), where seven Ma specimens and seven Mc (Miconia chamissois) specimens were sampled. Thus, 21 individuals were sampled in each study area, to give a total of 63 individuals.

In EA1, the plot located in Cerrado stricto sensu was close to vegetation in an advanced stage of conservation. The Ma specimens consisted of adult plants measuring up to $3 \mathrm{~m}$ that were sparsely distributed among dense vegetation of large size (4 to $8 \mathrm{~m}$ ) and which relied on abundant shade and dry soil; winds and grasses were absent. In the same study area, Mc was found in a plot located on the edge of a lagoon (Pindaíba), where the soil was soaked, the density of the vegetation provided different shade, humidity, and temperature than the plot located in Cerrado stricto sensu.

In EA2, the plot located in Cerrado stricto sensu was delimited and was undergoing regeneration. The vegetation measured between 3 and $6 \mathrm{~m}$, on average, and the canopy was discontinuous due to the distance between the plants. Light incidence 
was high, and the soil was dry and sandy. The Ma population density in this environment was high; the population was dispersed in the area and was becoming aggregated at the edges of the fragment. In this same study area, the other plot was located on the banks of the Bandeira stream, where the larger vegetation (4 to $10 \mathrm{~m}$ ) was dense and shaded. The soil was dark and moist and aggregated extensive Mc populations, as well as some Ma specimens growing in areas where the soil was drier.

EA3 was characterized by the dominant presence of preserved Cerrado stricto sensu, with vegetation measuring between 3 and $6 \mathrm{~m}$, on average. The canopy was discontinuous, and light and wind incidence among the plants was high. The soil was rocky. The presence of grasses was intense among the vegetation where Ma occurred with sparse distribution. Mc was found as populations aggregated inside large shaded depressions (furnas) where the moist soil became soaked in some stretches. In the "furnas", the plants were protected from wind. At the high and sunny edges, the soil was dry, and Ma was sparse.

\section{Botanical Materials}

Among Angiosperms, Melastomataceae Jussieu is the seventh most diverse and the second most common botanical family. It has pantropical distribution and high neotropic concentration, and it comprises about 166 genera and 4,570 species including herbs, shrubs, and trees. Thirty genera and 248 species occur in the state of São Paulo (Wanderley et al. 2009; Oliveira and Marquis, 2002). However, the conservation status of this family is worrisome because habitats that aggregate a high number of endemic species, with restricted and punctual distribution, are being destroyed (Morandi et al., 2020).

Miconia is the largest genus in terms of the number of species-approximately 1,050 Miconia species exist. In Brazil, there are 289 Miconia species, 122 of which are endemic (Zappi et al., 2015). Two species were selected for this study. One of them is Miconia albicans (SW.) Triana, which is distributed in South America and southern Mexico, is considered a pioneer species, and occurs in the fields of Cerrado, the Amazon Forest, Caatinga, and the Atlantic Forest (Neri et al., 2005; Allenspach and Dias, 2012). It is a shrub or small tree reaching up to $3 \mathrm{~m}$ in height, and it is popularly known as "pixirica" or "folha branca". In the state of São Paulo, this species can be 
found in forest edges of typical phytophysiognomies or in Cerrado regenerated areas (Durigan et al. 2004). The other species that was selected for this study is Miconia chamissois Naudin, which occurs from Mexico to southern Brazil and Argentina. M. chamissois is popularly known as "pixirica-açu". It is an exuberant and woody shrub that reaches up to $4.5 \mathrm{~m}$ in height and forms dense populations in the physiognomies of wet and flooded fields, riparian forest, and inner edge of the forests because it is highly tolerant to shaded environments (Romero and Martins 2002; Durigan et al. 2004; Wanderley et al. 2009). In the state of São Paulo, M. chamissois is an exclusive species of flooded areas and occurs along the Cerrado watercourses areas, which present distinct plant species composition and structural characteristics from the adjacent vegetation (Braga et al., 2001)

The Miconia species samples were identified on the basis of identification keys and the specialized literature (Romero and Martins, 2002; Souza, 2012; Wanderley et al., 2009; Zappi et al., 2015); the procedures that have already been established in the Angiosperms system were followed. The voucher specimens of the cataloged plants were confirmed and registered at the Herbarium of the Department of Biology, Laboratory of Plant Systematics, Faculty of Philosophy, Sciences, and Letters of Ribeirão Preto, University of São Paulo, Brazil (Herbarium, SPFR), under the number SPFR 16259 for M. albicans and SPFR 16260 for M. chamissois.

\section{Signal Collection}

\section{Signal Collection}

The bioelectrical signals were collected by using healthy and mature leaves from the third node of the branches of adult plants, where non-invasive gold-plated polarized surface electrodes (Neurosoft $0.85 \mathrm{Ihm}$ ) were fixed. The electrodes were fixed with conductive gel (Carbogel EEG gel) and adhesive tape. This system kept the pressure constant and prevented the electrodes from moving on the surface of the leaves while the signal was being acquired. Two electrodes were used on both the upper and lower sides of the leaves, and a ground reference electrode was fixed in the soil, close to the sampled plant (Figure 1). 
The signal was sampled at $200 \mathrm{~Hz}$, with two filters (High Pass and Notch), to eliminate external noise and noise from the equipment itself. Then, the signal was amplified by a factor of $10^{4}$ and sent wirelessly via the Bluetooth protocol to the software developed by the Laboratory of Computation and Applied Physics (LAFAC), according to Cabral et al. (2011).

The bioelectrical signal of the samples was obtained early in the morning to avoid physiological variability and depression of liquid photosynthesis around noon, when radiation becomes stronger, heat intensifies, air evaporative capacity increases, stomata ends close, intercellular $\mathrm{CO}_{2}$ concentration increases (there is a limitation of the photosynthetic process), and photochemical efficiency and water potential decrease (Larcher, 2006). To reduce the effects of the individual, short-period measurements (1 min) were taken and consisted in recording of 12,000 electrical signal amplitudes. Several measurements were conducted and stored; the measurements with less environmental interference (winds and sounds) were chosen as representative of the individual. The acquired signals were in the time domain, expressed in time (s) and amplitude $(\mathrm{mV})$, and in the frequency domain, expressed in magnitude $(\mathrm{Db})$ and frequency $(\mathrm{Hz})$, and they constituted a numerical database that was used to characterize them. The frequency domain behavior of the bioelectrical signals was observed through the average spectra processed from the signals obtained from the time domain specimens.

\section{Signal Processing and pattern analysis}

The PSD values of the bioelectrical signals sampled from the plants was calculated by using a computational algorithm implemented in the MatLab® environment. Several methods can be used to estimate PSD, the simplest one being the Welch approach with the periodogram method, which is used to determine the power density of the frequency components in a signal based on the Fourier-transform (FT). The Welch approach consists in estimating autocorrelation in the FT (obtained by averaging the autocorrelation of the segments of a bioelectrical signal sequence with $50 \%$ overlap), computing a power spectrum by using a fast Fourier-Transform (FFT) on each segment, and averaging these spectra (Welch, 1967; Barbe, Pintelon, and Schoukens, 2010) by considering the $95 \%$ confidence interval (Proakis, J.G.; Manolakis, 1996). 
The PSD values obtained from the plant's bioelectrical signal were plotted, and the raw data were divided into classes representing each plant specimen. The PSD raw data were labeled as Mad for PSD obtained for M. albicans growing in dry area, Maw for $M$. albicans growing in the wet area, and Mc for M. chamissois. Next, 50\% of the PSD raw data of each class was used to train a random forest algorithm implemented in python by using the h2o library with 50 trees. The remaining $50 \%$ of the PSD data was used to test if the PSD raw data from each specimen were statistically separable. The statistical separability of the PDS raw data was analyzed by using Mean Squared Error (MSE), which represents the difference between the original and the predicted values extracted by squaring the average difference over the dataset, to obtain the Root Mean Squared Error RMSE, which is the error rate by the square root of MSE, and the Confusion Matrix (CM). All these statistical metrics were obtained from the algorithm that was developed by using the h2o python library.

The h2o python library is an open-source machine-learning tool that implements advanced algorithms such as deep learning, boosting, and bagging ensembles, among others. The h2o library can handle big data rows in-memory by using in-memory compression, even in the case of a small cluster. The algorithm that was implemented by using the h2o python library was employed to verify whether the PSD values obtained for the bioelectrical signals of plant specimens belonging to different species and collected from different areas were statically separable. The PSD features calculated from the bioelectrical signals of plants were used to prepare an input feature vector to train and to validate machine learning with random forest algorithm as illustrated in Figure 2.

\section{(Fig. 2)}

The feature vector was prepared by employing seven components or variables obtained from the PSD values of seven individuals of a given species. Each feature vector component was assembled with spectral points; i.e., magnitude $(\mathrm{dB})$ versus frequency $(\mathrm{Hz})$ point obtained from PDS as illustrated in Figure 3. PSD has 1024 spectral points, so each specimen has 1024 points to represent its spectral species pattern. In this way, 1024 vector features were generated for each specimen of a given species. On the basis of this approach, the classification algorithm was trained and tested by using 18,450 feature vectors, which amounted to 129,150 variables. Fifty percent of the total dataset was used to train the machine learning, and $50 \%$ of the data 
set was used in the cross-validation test based on the Confusion Matrix (CM) method (Figure 3).

(Fig. 3)

\section{Results and discussion}

\section{Study Areas}

The Brazilian Cerrado is the second largest biome in Brazil: it covers 20\% or 204 million hectares of the Brazilian territory; it is situated between the Amazon and Atlantic Forests (without physical barriers); and it forms a large corridor of modestlooking xeromorphic vegetation (Oliveira and Marquis, 2002). The smaller size of the Cerrado vegetation can be explained by the fact that it resembles an inverted forest, where only about one third of the plant structure is on the soil surface. It is home to many Brazilian water springs; that is, it shelters the springs of important watersheds taking water to the Amazon Forest, the Atlantic Forest, Pantanal, and Caatinga.

Cerrado is characterized by well-defined climatic seasonality in the dry and rainy seasons, and it is considered one of the 36 hotspots of preservation. It concentrates more than $15 \%$ of all the biodiversity known in the world, and endemic species are abundant and coexist in 25 environments (Ramírez, Pringle, and Wantzen, 2008). However, $49 \%$ of the region occupied by the biome has been deforested and converted to pastures, crops, hydroelectric dams, mines, and urban areas, and only $8 \%$ of the native vegetation is protected. Apart from being a very diverse and heterogeneous system, Cerrado is very dependent on and sensitive to what happens in its surroundings. The great biodiversity of the Cerrado biome is believed to be linked to the diversity of the existing environments. Studies have tried to relate the physiognomies of the plants to environmental factors and have generally focused on associations with climate, soil classes, and fertility. Nevertheless, new insights into how living beings perceive and respond to stimuli from the environment are necessary (Gottsberger, 2006).

Biotic and abiotic interactions and the functional diversity of species over time generate an environmental gradient that acts as a filter that can shape the structure of the community in the Cerrado biome, resembling what happens in other similar biomes on the planet (Stubbs and Baston, 2004; Michalet et al., 2015; Soliveres, Smit, and 
Maestre, 2015). Microclimates are also relevant factors in ecosystems: they can mitigate the most severe conditions and facilitate unique community interactions (Mason et al., 2010; Molina-Venegas et al., 2018).

Studies have described some of the aspects that hinder the maintenance of Cerrado native plant species outside this biome. Examples of such aspects include great root development, greater difficulty in rooting some species, and morphophysiological adaptations to the typical Cerrado climatic stress (Cornwell, Schwilk, and Ackerly, 2006; Bulleri et al., 2016). Observations of Cerrado adult plants species have also reinforced the presence of exclusive characteristics of their development, such as the presence of xylopodium, an aspect that also prevents the maintenance of Cerrado species in a greenhouse (Melo et al., 2008). Xylopodium, whose origin (stem or root) has not yet been established, demonstrates a unique strategy of underground adaptation to explore water in deep soils (Apezzato Da Gloria, 2015).

Seedlings of the species M. albicans and M. chamissois are commercially available, but care must be adapted in terms of seed propagation, slow M. albicans growth rate (three or four years) and moderate $M$. chamissois growth rate, root development, and strict conditions of humidity and light for each species (Kuhlmann, 2018). Bearing in mind the various aspects attributed to the development of these plants and the complex synergy of these characteristics with numerous biotic and abiotic interactions in the natural environment, we have collected bioelectrical signals in loco.

\section{Spectral analysis}

Before collecting the bioelectrical signals, we tested the data acquisition system by sampling signals with open electrodes and then with electrodes placed on plant leaves. We then compared the PSD values of the signals obtained with open electrodes to the PSD values of the plant signals. Figure 4 shows that the PSD values of the signals acquired with open electrodes displayed the characteristics of a random signal with distribution resembling the distribution of a blank noise, which differed from the signal sampled with the electrode fixed in the plant. These results showed that the signal acquired from the plants were not randomly distributed in the frequency domain and were in agreement with the work of Cabral et al. 2011. 
We carried out this procedure in all the experimental areas to certify that the acquired signals were free of interferences other than the background noise fluctuation of the open electrodes.

The bioelectrical signals obtained from the Ma (M. albicans) and Mc ( $M$. chamissois) species in the three experimental areas revealed spectra with small peaks distributed along with the frequencies. This PSD behavior could be related to how the species interacts with environmental variables like the incidence of light, soil, and others. The plant can recognize environmental factors; for example, temperature, humidity, atmospheric pressure, and light intensity, as observed in the study of Souza et al. (2017), who even used the term "electroma" to refer to the electrical dimension of the plant as a response to the environmental variables.

The shape of the spectra obtained in the three study areas suggested the presence of a frequency pattern in the bioelectrical behavior, which was different for each of the botanical species (Figure 5) when the signals were sampled in the same season.

(Fig.5)

Figure 6 shows the average of the spectra recorded for the Ma and Mc bioelectrical signals collected in the three areas at different times and then averaged and plotted with their standard deviation. Given that the standard deviations did not overlap in the spectra in Figure 6, we can suggest that each species has distinct frequency behavior in the mean.

(Fig.6)

\section{Pattern analysis}

The average spectral data were not enough to ensure that specimens had a spectral pattern, so we went back to using all the spectra of all the specimens to train an RF algorithm and then check whether there was a frequency pattern in each specimen by measuring the RF classification rates after Training. We trained the RF algorithm by using the parameters listed in Table 2. 
Table 3 shows the CM for classification of the feature vector representing the spectral pattern of Ma and Mc by the RF classifier. The CM refers to the output of the algorithm when 9217 individual PSD samples of the bioelectrical signals from the plants were presented. The data indicated that only 4 PSD values were classified incorrectly, which led to an error rate of 0.0004 , hence a very small error rate. Additionally, the spectral average was not used in the RF experiments.

Applying machine learning in plant classification effectively helps to discover existing patterns in the various characteristics of plants. In this sense, this study agreed with other literature results based on the use of machine learning as a tool to recognize patterns in plants (see the work of Gokhale et al., 2020). Regarding the existence of plant bioelectrical patterns that can be classified with machine learning, the results of this article agreed with the results obtained by Nambo et al. (2018), who used machine learning to show the existence of bioelectrical patterns in living plants that are sensitive to environmental variables.

Finally, analysis of the mean of the spectra considering their standard deviation and of the results obtained with machine learning indicated bioelectrical characteristics that were specific to the species. This is important because bioelectricity could become a new tool to monitor and to characterize plants in loco.

\section{Conclusion}

We have confirmed the hypothesis that plant bioelectrical signals can be collected in loco. The methodology that we used to acquire the bioelectrical signals revealed that the plant electrical signals differ from the noise pattern that could interface with the signal, and the frequency spectrum showed a characteristic average pattern for each species.

Additionally, the developed experiments generated an important database of samples of bioelectrical amplitudes for analysis in the time and frequency domain.

The frequency domain analyses based on the PSD and machine learning techniques suggested the existence of a bioelectrical pattern that is characteristic of each species, M. albicans and M. chamissois, even though the data were acquired in different Cerrado physiognomies. Comparison of the oscillatory behavior of the species left no 
doubt about their bioelectrical characteristics, the feasibility of collecting the bioelectrical signals, the presence of a bioelectrical pattern in Miconia, and the influence of environmental factors on them.

From the point of view of experimental botany, new concepts and new questions must be formulated to advance understanding of the communicative nature of plants and their interaction with the environment (Baluška and Mancuso, 2009). The results of this on-site technique represent a new methodology to acquire noninvasive information, that can be associated with other physiological, chemical, and ecological aspects of plants.

\section{Acknowledgements}

The authors acknowledge the grants provided by Conselho Nacional de Desenvolvimento Científico e Tecnológico $(\mathrm{CNPq})$ and Fundação de Amparo à Pesquisa do Estado de São Paulo (FAPESP) (Universal Program 441335/2014-4 and \#2016/10313-4, respectively), and the financial support of Coordenação de Aperfeiçoamento de Pessoal de Nível Superior, Brazil (CAPES, Finance Code 001). VMM Gimenez thanks CAPES for a fellowship, and PM Pauletti and EJX Costa thank CNPq for fellowships.

\section{Author's Contributions}

Valéria M M Gimenez: Methodology, Investigation, Writing;

Patricia M Paulleti: Visualization, Investigation, Writing-Review \& Editing, Funding acquisition;

Ana C S Silva: Formal analysis, Review \& Editing;

Ernane J X Costa: Conceptualization, Supervision, Writing-Original draft preparation, Methodology, Funding acquisition;

\section{Data Availability}

The raw data of the PDS spectra used during the study are available from the corresponding author by request. 


\section{References}

Ali, M., Sugimoto,K., Ramadan, A. and Arimura, G.I. . 2013. "Memory of Plant Communications for Priming Anti-Herbivore Responses." Scientific Reports 3 (1): 1872. https://doi.org/10.1038/srep01872.

Allenspach, N. and Dias, MM. 2012. "Frugivory by Birds on Miconia Albicans (MELASTOMATACEAE), in a Fragment of Cerrado in São Carlos, Southeastern Brazil." Brazilian Journal of Biology 72 (2): 407-13. https://doi.org/10.1590/S151969842012000200024.

Apezzato Da Gloria, B. 2015. Morfologia de Sistemas Subterrâneos de Plantas/Morfology of Plant Underground Systems. 3rd ed. Belo Horizonte - MG: 3i Ed. https://www.si.edu/object/siris_sil_1075111.

Baldin, A. V., Dosko, S.I., Kucherov, K.V., Bin, L., Spasenov, A.Y., Utenkov, V.M. and Zhuk, D.M. 2020. "ECG Signal Spectral Analysis Approaches for HighResolution Electrocardiography." In , 197-209. https://doi.org/10.1007/978-3-03012082-5_18.

Baluška, F. and Mancuso, S. 2009. "Plant Neurobiology: From Sensory Biology, via Plant Communication, to Social Plant Behavior." Cognitive Processing 10 (S1): 3-7. https://doi.org/10.1007/s10339-008-0239-6.

Barbe, K., Pintelon, R. and Schoukens, J.. 2010. "Welch Method Revisited: Nonparametric Power Spectrum Estimation Via Circular Overlap." IEEE Transactions on Signal Processing 58 (2): 553-65. https://doi.org/10.1109/TSP.2009.2031724.

Braga, A.R.S., Rezende, A.V., Milhomem, A.S., Araujo, A.F.B. Camargo, A.J.A., Sevilha, A.C., Roosevelt, A. et al. 2001. Cerrado: Caracterização e Recuperação de Matas de Galeria. Edited by J F Ribeiro, Fonseca C E L, and J C Sousa-Sila. 1st ed. Planaltina: EMBRAPA cerrados.

Breiman, L. 2001. "Random Forests." Machine Learning 45: 5-32. https://doi.org/doi.org/10.1023/A:1010933404324.

Bulleri, F., Bruno, J.F., Silliman, B.R. and Stachowicz, J.J. 2016. "Facilitation and the Niche: Implications for Coexistence, Range Shifts and Ecosystem Functioning." Edited by Richard Michalet. Functional Ecology 30 (1): 70-78. https://doi.org/10.1111/1365-2435.12528.

Cabral, E.F., Pecora,P.C., Arce, A.I.C., Tech, A.R.B. and Costa, E.J.X. 2011. "The Oscillatory Bioelectrical Signal from Plants Explained by a Simulated Electrical Model and Tested Using Lempel-Ziv Complexity." Computers and Electronics in Agriculture 76 (1). https://doi.org/10.1016/j.compag.2010.12.001. 
Calvo, P. 2016. "The Philosophy of Plant Neurobiology: A Manifesto." Synthese 193 (5): 1323-43. https://doi.org/10.1007/s11229-016-1040-1.

Calvo, P., and Friston, F. 2017. "Predicting Green: Really Radical (Plant) Predictive Processing." Journal of The Royal Society Interface 14 (131): 20170096. https://doi.org/10.1098/rsif.2017.0096.

Calvo, P., Sahi,V.P. and Trewavas,A. 2017. "Are Plants Sentient?" Plant, Cell \& Environment 40 (11): 2858-69. https://doi.org/10.1111/pce.13065.

CEPAGRI. 2017. "Centro de Pesquisas Metereológicas e Climáticas Aplicadas a Agricultura.” Metereologia UNICAMP. 2017. www.cepagri.unicamp.br.

Chen, Y., Zhao, D.J., Zi-, Wang, Z., Wang, Z.Y.W., Tang, G. and Huang, L.. 2016. "Plant Electrical Signal Classification Based on Waveform Similarity." Algorithms 9 (4): 70. https://doi.org/10.3390/a9040070.

Cornwell, W.K., Schwilk, D.W. and Ackerly, D.D. 2006. "A Trait-Based Test for Habitat Filtering: Convex Hull Volume." Ecology 87 (6): 1465-71. https://doi.org/https://doi.org/10.1890/0012-9658(2006)87[1465:ATTFHF]2.0.CO;2.

Costa, E.J.X. and Cabral, E.F. 2000. "EEG-Based Discrimination between Imagination of Left and Right Hand Movements Using Adaptive Gaussian Representation." Medical Engineering and Physics 22 (5). https://doi.org/10.1016/S1350-4533(00)00051-5.

Davies, E. 2006. "Electrical Signals in Plants: Facts and Hypotheses." In Plant Electrophysiology, 407-22. Berlin, Heidelberg: Springer Berlin Heidelberg. https://doi.org/10.1007/978-3-540-37843-3_17.

Durigan, G.; Baitello, J.B.; Franco, G.A.D.C.; Siqueira, M.F. 2004. Plantas Do Cerrado Paulista: Imagens de Uma Paisagem Ameaçada. Edited by EMBRAPA Florestas (CNPF). 1 ed.

Dinant, S. and Lemoine, R. 2010. "The Phloem Pathway: New Issues and Old Debates." Comptes Rendus Biologies $333 \quad$ (4): $307-19$. https://doi.org/10.1016/j.crvi.2010.01.006.

Fong, S., Cho, K., Mohammed, O., Fiaidhi, J. and Mohammed, S. 2016. "A Time Series Pre-Processing Methodology with Statistical and Spectral Analysis for Classifying Non-Stationary Stochastic Biosignals." The Journal of Supercomputing 72 (10): 3887-3908. https://doi.org/10.1007/s11227-016-1635-9.

Fromm, J. and Lautner, S. 2007. "Electrical Signals and Their Physiological Significance in Plants." Plant, Cell \& Environment 30 (3): 249-57. https://doi.org/10.1111/j.1365-3040.2006.01614.x.

Gokhale, A., Babar, S., Gawade, S. and Jadhav, S. 2020. "Identification of Medicinal Plant Using Image Processing and Machine Learning." In , 272-82. https://doi.org/10.1007/978-981-15-4029-5_27.

Gottsberger, G., Silberbauer-Gottsberger, I. 2006. Life in the Cerrado. 1. ed. Ulm: 
Reta Verlag.

Hasegawa, P. M., Bressan, R.A., Zhu, J.K. and Bohnert, H.J.. 2000. "Plant Cellular and Molecular Responses to High Salinity." Annual Review of Plant Physiology and Plant Molecular $\quad$ Biology $\quad 51 \quad$ (1): https://doi.org/10.1146/annurev.arplant.51.1.463.

Hernandez, P. A., I. Franke, I., Herzog, S.K., Pacheco, V., Paniagua, L., Quintana, L.H.L., Soto, A. et al. 2008. "Predicting Species Distributions in PoorlyStudied Landscapes." Biodiversity and Conservation 17 (6): 1353-66. https://doi.org/10.1007/s10531-007-9314-z.

Huber, A. E. and Bauerle, T.L. 2016. "Long-Distance Plant Signaling Pathways in Response to Multiple Stressors: The Gap in Knowledge." Journal of Experimental Botany 67 (7): 2063-79. https://doi.org/10.1093/jxb/erw099.

Kuhlmann, M. 2018. Frutos e Sementes Do Cerrado - Espécie Atrativas Para a Fauna. Edited by Peres M. K. 1st ed. Brasilia - DF: M. K. Peres.

Larcher, W. 2006. Ecofisiologia Vegetal. Edited by RIMA Editora. 3 ed. São Carlos SP.

Loof, Arnold De. 2016. "The Cell's Self-Generated 'Electrome': The Biophysical Essence of the Immaterial Dimension of Life?" Communicative \& Integrative Biology 9 (5): e1197446. https://doi.org/10.1080/19420889.2016.1197446.

Manshouri, N., Maleki, M. and Kayikcioglu, T. 2018. "Power Spectrum Analysis of EEG for Watching 2D \&amp; 3D Videos and Resting State." In 2018 26th Signal Processing and Communications Applications Conference (SIU), 1-4. IEEE. https://doi.org/10.1109/SIU.2018.8404394.

Mason, N.W. H., Peltzer, D.A., Richardson, S.J., Bellingham, P.J. and Allen, R.B. 2010. "Stand Development Moderates Effects of Ungulate Exclusion on Foliar Traits in the Forests of New Zealand." Journal of Ecology 98 (6): 1422-33. https://doi.org/10.1111/j.1365-2745.2010.01714.x.

Melo, J T, Torres, R.A.A., Silveira, C.E.S. and Caldas, L.S. 2008. "Coleta, Propagação e Desenvolvimento Inicial de Plantas Do Cerrado." In Cerrado: Ecologia e Flora, edited by S M Sano, S P Almeida, and J F Ribeiro, 1st ed., 1279. Piracicaba: EMBRAPA-DF.

Michalet, R., Chen, S.Y., An, L.S., Wang, X.T., Wang, Y.X., Guo, P., Ding, C.C. and Xiao,S.. 2015. "Communities: Are They Groups of Hidden Interactions?" Edited by Stephen Roxburgh. Journal of Vegetation Science 26 (2): 207-18. https://doi.org/10.1111/jvs.12226.

Molina-Venegas, R., Aparicio, A., Lavergne, S. and Arroyo, J.. 2018. "Soil Conditions Drive Changes in a Key Leaf Functional Trait through Environmental Filtering and Facilitative Interactions." Acta Oecologica 86 (January): 1-8. https://doi.org/10.1016/j.actao.2017.11.008.

Morandi, D.T., França, L.C.J., Menezes, E.S., Machado, E.L.M., Silva, M.D. and 
Mucida, D.P.. 2020. "Delimitation of Ecological Corridors between Conservation Units in the Brazilian Cerrado Using a GIS and AHP Approach." Ecological Indicators 115 (August): 106440. https://doi.org/10.1016/j.ecolind.2020.106440.

Nambo, Hidetaka, Imam Tahyudin, Takeo Nakano, and Tetsuya Yamada. 2018. "Comparison of Deep Learing Algorithms for Indoor Monitoring Using Bioelectric Potential of Living Plants." In 2018 3rd International Conference on Information Technology, Information System and Electrical Engineering (ICITISEE), 110-13. IEEE. https://doi.org/10.1109/ICITISEE.2018.8720992.

Neri, Andreza Viana, Érica Pereira de Campos, Temilze Gomes Duarte, João Augusto Alves Meira Neto, Alexandre Francisco da Silva, and Gilmar Edilberto Valente. 2005. "Regeneração de Espécies Nativas Lenhosas Sob Plantio de Eucalyptus Em Área de Cerrado Na Floresta Nacional de Paraopeba, MG, Brasil." Acta Botanica Brasilica 19 (2): 369-76. https://doi.org/10.1590/S0102-33062005000200020.

Oliveira;, Paulo S., and Robert J. Marquis. 2002. The Cerrados of Brazil. Edited by Paulo S. Oliveira and Robert J. Marquis. Columbia University Press. https://doi.org/10.7312/oliv12042.

Oparin, Ilya, Ondrej Glembek, Lukas Burget, and Jan Cernocky. 2008. "Morphological Random Forests for Language Modeling of Inflectional Languages." In 2008 IEEE Spoken Language Technology Workshop, 189-92. IEEE. https://doi.org/10.1109/SLT.2008.4777872.

Pereira, Danillo Roberto, João Paulo Papa, Gustavo Francisco Rosalin Saraiva, and Gustavo Maia Souza. 2018. "Automatic Classification of Plant Electrophysiological Responses to Environmental Stimuli Using Machine Learning and Interval Arithmetic." Computers and Electronics in Agriculture 145: 35-42. https://doi.org/10.1016/j.compag.2017.12.024.

Proakis, J.G.; Manolakis, D G. 1996. Digital Signal Processing- Principles, Algoritms and Applications. Edited by I N C Prentice-Hall International. 3th editio.

Ramírez, Alonso, Catherine M. Pringle, and Karl M. Wantzen. 2008. "Tropical Stream Conservation." In Tropical Stream Ecology, 285-304. Elsevier. https://doi.org/10.1016/B978-012088449-0.50012-1.

Romero, R. and Martins, A.B.. 2002. "Melastomataceae Do Parque Nacional Da Serra Da Canastra, Minas Gerais, Brasil." Revista Brasileira de Botânica 25 (1): 19-24. https://doi.org/10.1590/S0100-84042002000100004.

Soliveres, S., Smit, C. and Maestre, F.T.. 2015. "Moving Forward on Facilitation Research: Response to Changing Environments and Effects on the Diversity, Functioning and Evolution of Plant Communities." Biological Reviews 90 (1): 297-313. https://doi.org/10.1111/brv.12110.

Souza, G.M., Ferreira, A.S., Saraiva, G.F.R. and Toledo, G.R.A.. 2017. "Plant 'Electrome' Can Be Pushed toward a Self-Organized Critical State by External Cues: Evidences from a Study with Soybean Seedlings Subject to Different Environmental Conditions." Plant Signaling \& Behavior 12 (3): e1290040. https://doi.org/10.1080/15592324.2017.1290040. 
Souza, G.M., Pincus, S.M. and Monteiro, J.A.F.. 2005. "The Complexity-Stability Hypothesis in Plant Gas Exchange under Water Deficit." Brazilian Journal of Plant Physiology 17 (4): 363-73. https://doi.org/10.1590/S1677-04202005000400004.

Souza, V.C. 2012. Botânica Sistemática: Guia Ilustrado Para Identificação Das Famílias de Fanerógamas Nativas e Exóticas No Brasil, Baseado Em APG III. Nova Odessa.

Stubbs, W.J. and Baston,W.J. 2004. "Evidence for Limiting Similarity in a Sand Dune Community." Journal of Ecology 92 (4): 557-67. https://doi.org/10.1111/j.00220477.2004.00898.x.

Toledo, G.R.A., Parise, A.G., Simmi, F.Z., Costa, A.V.L., Senko,L.G.S., Debono, M.W. and Souza, G.M. 2019. "Plant Electrome: The Electrical Dimension of Plant Life." Theoretical and Experimental Plant Physiology 31 (1): 21-46. https://doi.org/10.1007/s40626-019-00145-x.

Trewavas, A. 2007. "Response to Alpi et Al.: Plant Neurobiology - All Metaphors Have Value." Trends in Plant Science 12 (6): 231-33. https://doi.org/10.1016/j.tplants.2007.04.006.

Trewavas, A. and Baluška, F. 2011. "The Ubiquity of Consciousness." EMBO Reports 12 (12): 1221-25. https://doi.org/10.1038/embor.2011.218.

Verikas, A., Gelzinis, A. and Bacauskiene, M.. 2011. "Mining Data with Random Forests: A Survey and Results of New Tests." Pattern Recognition 44 (2): 330-49. https://doi.org/10.1016/j.patcog.2010.08.011.

Vodeneev, V. A., Katicheva, L.A. and Sukhov, V.S. 2016. "Electrical Signals in Higher Plants: Mechanisms of Generation and Propagation." Biophysics 61 (3): 505-12. https://doi.org/10.1134/S0006350916030209.

Vodeneev, V., Akinchits, E. and Sukhov, V.. 2015. "Variation Potential in Higher Plants: Mechanisms of Generation and Propagation." Plant Signaling \& Behavior 10 (9): e1057365. https://doi.org/10.1080/15592324.2015.1057365.

Volkov, A.G., and Markin, V.S.. 2015. "Active and Passive Electrical Signaling in Plants.” In , 143-76. https://doi.org/10.1007/978-3-319-08807-5_6.

Volkov, A.G., ed. 2012. Plant Electrophysiology. Berlin, Heidelberg: Springer Berlin Heidelberg. https://doi.org/10.1007/978-3-642-29119-7.

Volkov, A.G., Nyasani, E.K., Tuckett, C., Scott, J.M., Jackson, M.M.Z., Greeman, E.A., Greenidge, A.S., Cohen, D.O., Volkova, M.I. and Shtessel, Y.B.. 2017. "Electrotonic Potentials in Aloe Vera L.: Effects of Intercellular and External Electrodes Arrangement." Bioelectrochemistry 60-68. https://doi.org/10.1016/j.bioelechem.2016.10.004.

Wanderley, M.G.L., Shepherd, G.J., Giulietti, A.M. and Melhem, T.S.. 2009. Flora Fanerogâmica Do Estado de São Paulo. São Paulo: Instituto de Botânica, São Paulo.

Welch, P. 1967. "The Use of Fast Fourier Transform for the Estimation of Power 
Spectra: A Method Based on Time Averaging over Short, Modified Periodograms." IEEE Transactions on Audio and Electroacoustics 15 (2): 70-73. https://doi.org/10.1109/TAU.1967.1161901.

Zappi, D.C., Filardi, F.L.R., Leitman, P., Souza, V.C., Walter, B.M.T., Pirani, J.R., Morim, M.P. et al. 2015. "Growing Knowledge: An Overview of Seed Plant Diversity in Brazil." Rodriguésia 66 (4): 1085-1113. https://doi.org/10.1590/21757860201566411. 
Table 1 - Location and climate classification according to Köpen-Geiger including coordinates and altitude $(\mathrm{m})$ for year 2016 of the study areas when they were used as samples (CEPAGRI 2017).

\begin{tabular}{|c|c|c|c|c|c|c|c|c|}
\hline $\begin{array}{c}\text { Study } \\
\text { area }\end{array}$ & Climate & Coordinates & $\begin{array}{l}\text { Altitude } \\
\text { (m) }\end{array}$ & $\begin{array}{c}\mathrm{T} \\
\min \\
\left({ }^{\circ} \mathrm{C}\right)\end{array}$ & $\begin{array}{c}\mathrm{T} \\
\max \\
\left({ }^{\circ} \mathrm{C}\right)\end{array}$ & $\begin{array}{c}\mathrm{R} \\
\min \\
(\mathrm{mm})\end{array}$ & $\begin{array}{c}\mathrm{R} \\
\max \\
(\mathrm{mm})\end{array}$ & $\begin{array}{c}\mathrm{R} \\
\text { average } \\
(\mathrm{mm})\end{array}$ \\
\hline EA1 & Cwa & $\begin{array}{c}\text { S } 21^{\circ} 36^{\prime} \\
\text { NO } 47^{\circ} 15^{\prime}\end{array}$ & 620 & 8 & 29.3 & 23 & 237 & 1395 \\
\hline EA2 & Aw & $\begin{array}{l}\text { S } 21^{\circ} 33^{\prime} \\
\text { NO } 47^{\circ} 51^{\prime}\end{array}$ & $515-650$ & 10.8 & 29.6 & 26.6 & 273.6 & 1516 \\
\hline EA3 & Cwb & $\begin{array}{l}\mathrm{S} 20^{\circ} 08^{\prime} \\
\mathrm{NO} 47^{\circ} 16^{\prime}\end{array}$ & 1040 & 9.4 & 28.5 & 18 & 286.9 & 1545 \\
\hline
\end{tabular}

* minimum temperature $\left(\mathrm{T} \min \left({ }^{\circ} \mathrm{C}\right)\right)$, maximum temperature $\left(\mathrm{T} \max \left({ }^{\circ} \mathrm{C}\right)\right)$, minimum rainfall $(\mathrm{R}$ $\min (\mathrm{mm}))$, maximum rainfall $(\mathrm{R} \max (\mathrm{mm}))$, and annual rainfall $(\mathrm{R}$ annual $(\mathrm{mm}))$, EA1 Campus/USP in Pirassununga, EA2 - Jataí Ecological Station (EEJ), and EA3 - Furnas do Bom Jesus State Park (PEFBJ).

Table 2 - Python's h2o Random Forest library model summary used to classify the PDS from the bioelectrical signals of the plants.

\begin{tabular}{ccccc}
\hline $\begin{array}{c}\text { Number of } \\
\text { trees }\end{array}$ & $\begin{array}{c}\text { Number of } \\
\text { internal trees }\end{array}$ & $\begin{array}{c}\text { Model size in } \\
\text { bytes }\end{array}$ & MSE & Mean Per-Class Error \\
\hline 50 & 50 & 111239 & 0.019 & 0.000406 \\
\hline
\end{tabular}

Table 3 - Confusion Matrix for cross validation data.

\begin{tabular}{lllll}
\hline \multicolumn{1}{c}{ Predicted } & Ma & Mc & Error & Rate \\
Actual & & & & \\
\hline Ma & 6073 & 3 & 0.0005 & $(3.0 / 6076.0)$ \\
Mc & 1 & 3140 & 0.0003 & $(1.0 / 3141.0)$ \\
Total & 6074 & 3143 & 0.0004 & $(4.0 / 9217.0)$ \\
\hline
\end{tabular}




\section{Figure Legends}

Fig.1 - Gold electrode placement with Carbogel EEG gel on plant leaves.

Fig.2 - Methodology for pattern analysis with the random forest algorithm.

Fig.3 - Feature vector generated with spectral points representing each species.

Fig.4 - Spectral comparison between signals acquired from the plant and noises.

Fig.5 - Difference in the spectral pattern of the species Ma (a) and Mc (b) for areas EA1, EA2 , and EA3.

Fig.6 - Mean spectral pattern comparison \pm sd of 42 samples of Ma and Mc in different areas 


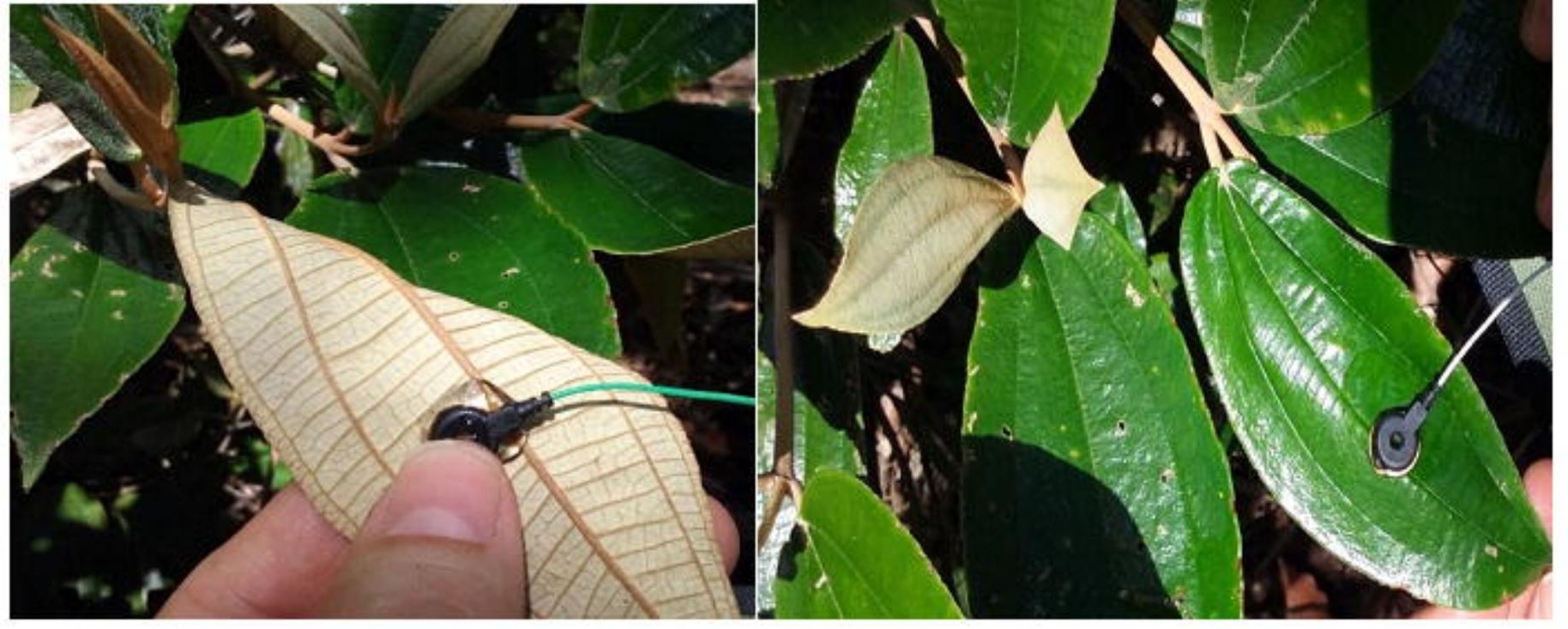




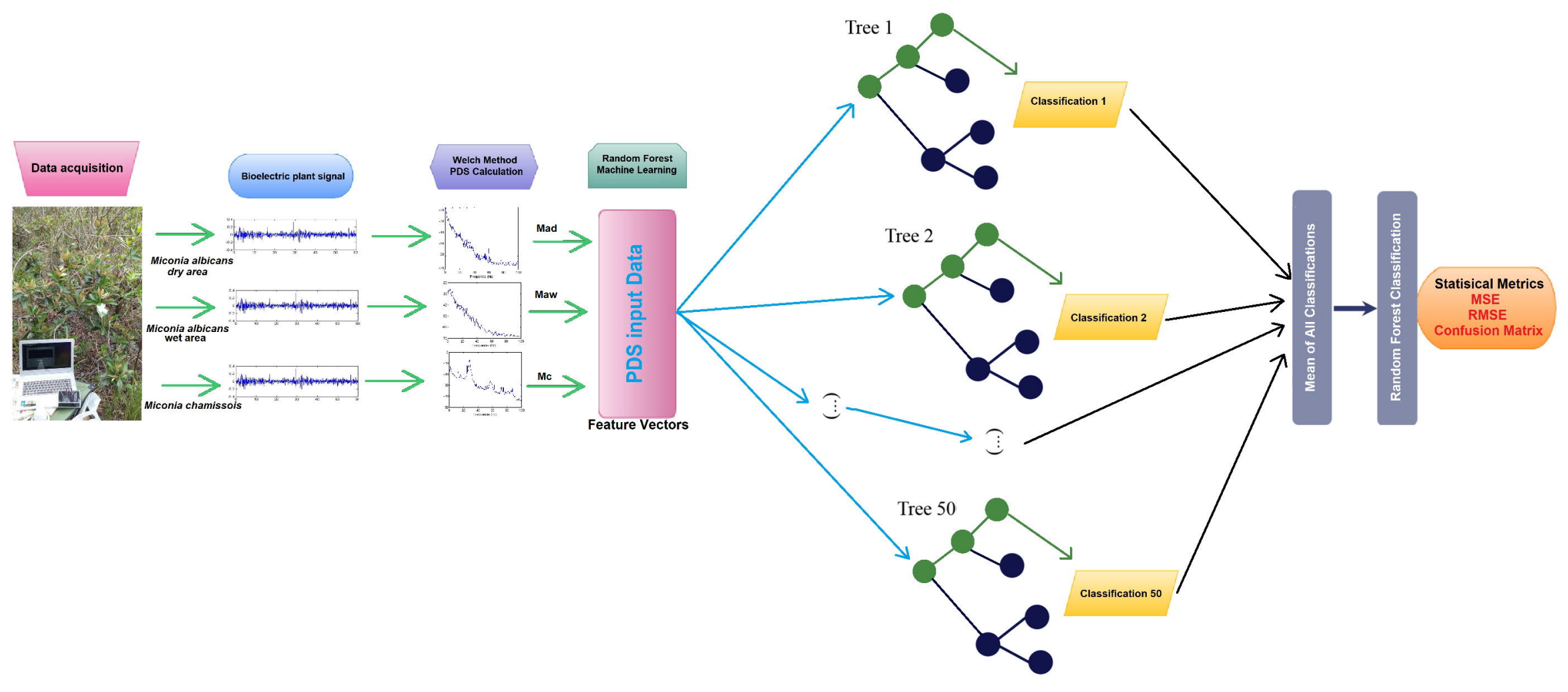




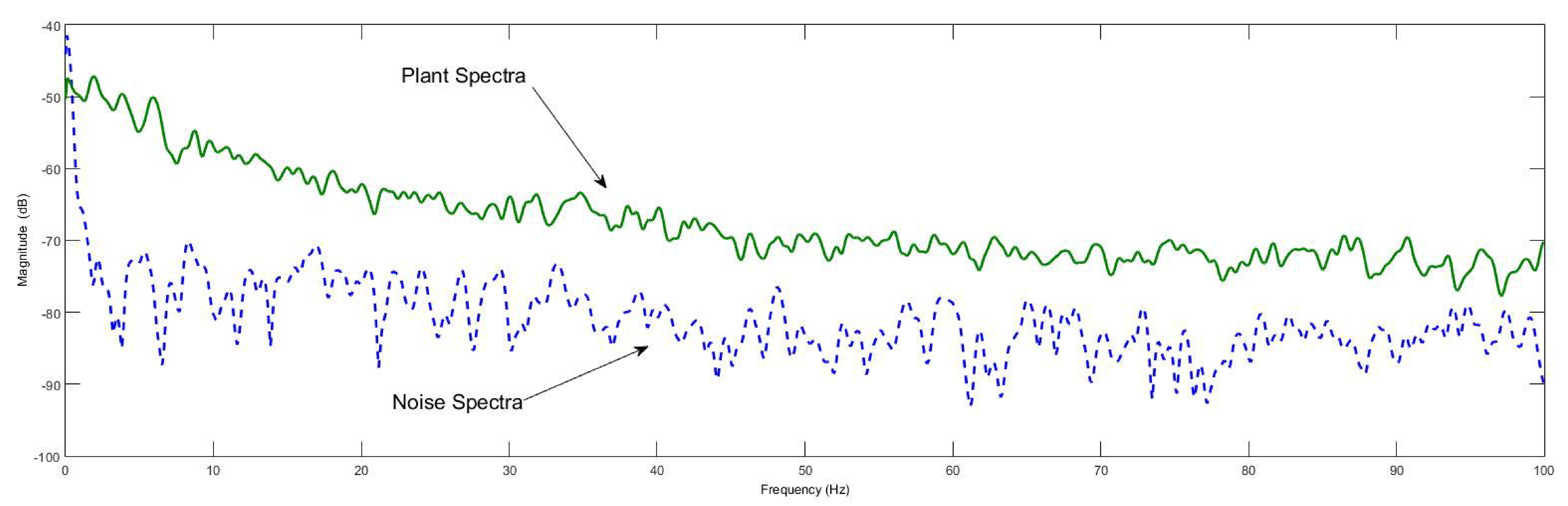




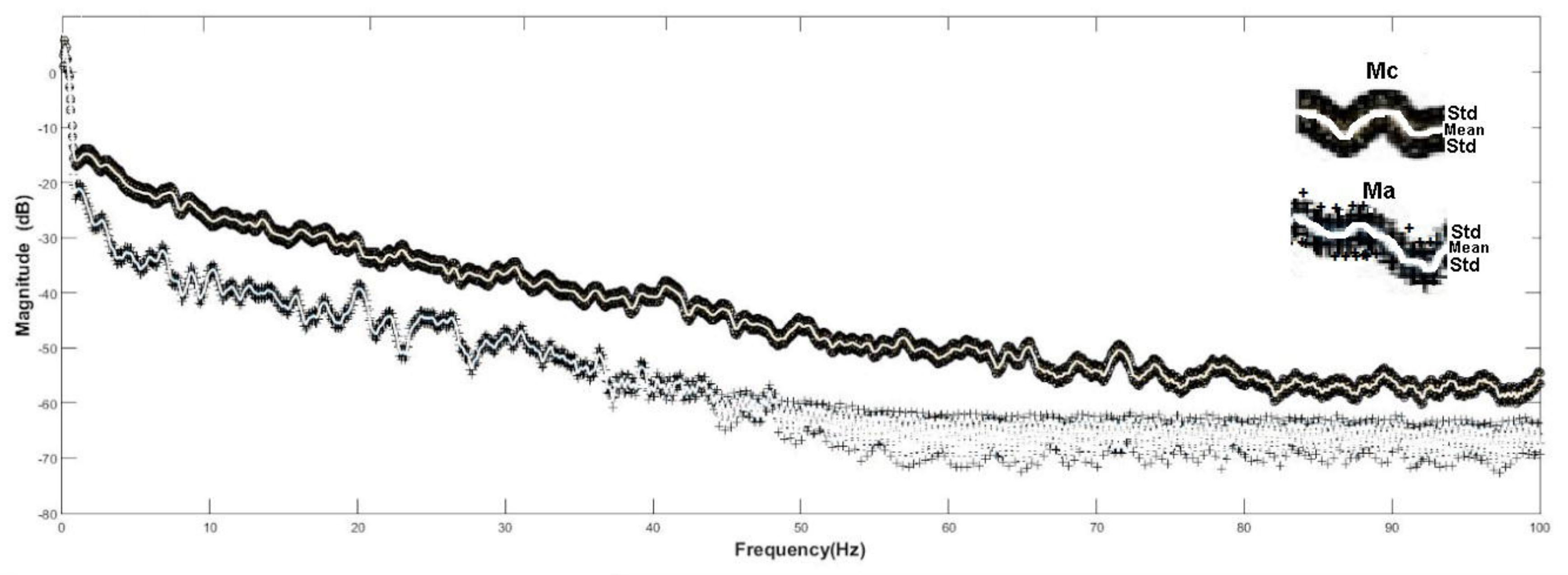

